\title{
Long survival in acute myelogenous leukaemia: an international collaborative study
}

\author{
J A WHITTAKER, P REIZENSTEIN, SHEILA T CALLENDER, G G CORNWELL, \\ I W DELAMORE, R P GALE, M GOBBI, P JACOBS, B LANTZ, A T MAIOLO, J K H REES, \\ E J VAN SLYCK, H VU VAN
}

\begin{abstract}
A group of 82 adult patients with acute myelogenous leukaemia who had survived in continuous first remission for more than three years was studied. These long-surviving patients were being treated at 12 referral centres in Europe and the USA, and they were compared with other patients with acute myelogenous leukaemia from 10 of these centres. There was no clear difference in the amount of induction chemotherapy or the time taken to achieve remission. Immunotherapy was not found to improve chances of long-term survival. The 82 patients were also compared with a group of 115 patients who had survived in remission for less than three years. There was no appreciable difference in the number of blood or marrow myeloblasts between these two groups at presentation, but the long survivors had significantly higher initial platelet counts and were slightly younger. The long survivors also tended to have a lower total white
\end{abstract}

Department of Haematology, Welsh National School of Medicine and University Hospital of Wales, Cardiff CF4 4XN

J A WHITTAKER, MD, FRCP, senior lecturer in haematology

Division of Haematology, Karolinska Hospital, Stockholm, Sweden P REIZENSTEIN, MD, chief

B LANTZ, MD, assistant haematologist

Nuffield Department of Clinical Medicine, John Radcliffe Hospital, Headington, Oxford

SHEILA T CALLENDER, MD, FRCP, clinical reader

Department of Medicine, Dartmouth Medical School, Hanover, New Hampshire, USA

G G CORNWELL, MD, chief, section of haematology and oncology

University Department of Clinical Haematology, the Royal Infirmary, Manchester M13 9WL

I W DELAMORE, FRCP, FRCPATH, physician in charge

UCLA School of Medicine, Los Angeles, California, USA

R P GALE, MD, associate professor of medicine

Istituto di Ematologia "Lorenzo ed Ariosto Seràgnoli," University of Bologna, Bologna, Italy

$M$ GOBBI, MD, senior university researcher

University of Cape Town Leukaemia Centre and Department of Haematology, Groote Schuur Hospital, Observatory, Cape, South Africa

P JACOBS, MD, PHD, professor of haematology

Clinica Medica I, University of Milan, Milan, Italy

A T MAIOLO, MD, associate professor of clinical medicine

Department of Haematological Medicine, University of Cambridge, Cambridge CB2 2QL

J K H REES, MB, MRCP, lecturer

Henry Ford Hospital, Detroit, Michigan, USA

E J VAN SLYCK, MD, head, section of haematology

Department of Haematology, Hôpital Edouard-Herriot, Lyons, France

H VU VAN, MD, haematologist cell count at presentation and lower granulocyte counts; there was no obvious explanation for these differences.

Eight of the 82 patients relapsed from three to four years after remission and two (of 69 patients) after four to five years. Thereafter relapse was rare, and it seems likely that some of the 40 patients who have survived for five years or more are cured.

\section{Introduction}

There have been several studies of long-surviving patients with acute leukaemia,,$^{1-3}$ but these have been concerned principally with acute lymphoblastic leukaemia. Many of the remissions for acute myelogenous leukaemia have been relatively short, ${ }^{4}$ though remission rates have improved rapidly and some authors have suggested that as many as $10 \%$ of patients with acute myelogenous leukaemia may survive a long $\operatorname{time}^{\mathbf{B}}$; a detailed report of 16 long-surviving patients has been published."

We studied a group of 82 adults with acute myelogenous leukaemia, all of whom had survived for at least three years in continuous first remission. We compared these patients with two other groups of patients with acute myelogenous leukaemia who survived for less than three years.

\section{Patients and methods}

Information was obtained on 82 patients in 12 centres in Europe and the United States (table I) by means of a questionnaire. All had been in continuous complete remission for at least three years and with one exception (aged 12 years) were adults aged 15-74 years at the time they presented. Details of age, sex, initial blood counts, induction treatment, maintenance treatment, immunotherapy, remission duration, and duration of survival were analysed for all patients.

TABLE I-Centre of origin of 82 long-surviving patients with acute myelogenous leukaemia

\begin{tabular}{lclclc}
\hline & $\begin{array}{c}\text { No of } \\
\text { patients }\end{array}$ & & $\begin{array}{c}\text { No of } \\
\text { patients }\end{array}$ & $\begin{array}{c}\text { No of } \\
\text { patients }\end{array}$ \\
\hline Bologna & 4 & Dartmouth & 5 & Oxford & 3 \\
Cambridge & 6 & Detroit & 3 & Manchester & 14 \\
Cape Town & 3 & Los Angeles & 8 & Milan & 5 \\
Cardiff & 6 & Lyons & 9 & Sweden & 16 \\
\hline & & & & & Total 82
\end{tabular}

Most patients from 10 of the 12 centres had been included in large trials of induction chemotherapy and it was possible to compare the induction treatment received by 63 long survivors with that of a much larger group of patients who survived for less than three years. In addition, during remission the patients from eight of the 12 centres had been included in controlled trials in which immunotherapy during remission had been compared with chemotherapy alone or with no treatment. Consequently, we were able to study the contribution of immunotherapy to long survival. The initial blood counts and the percentage of bone marrow blast cells in our patients were compared with those in 115 patients with acute myelogenous leukaemia reaching remission at one of the centres (Cardiff) during a similar period (1972-8). Possible statistical differences were examined using Student's $t$ test. 
Bone marrow smears taken at presentation from the long-surviving patients were reviewed to establish the diagnosis and to subdivide the patients into groups according to the classification of leukaemia proposed by the French-American-British (FAB) co-operative group. ${ }^{8}$ Sixty-one marrows were examined by one of the authors (JAW). The remaining 21 marrows were reviewed at the centres of origin, but one centre did not use the FAB classification.

\section{Results}

Leukaemia subtype-Review of bone marrow smears confirmed that the original diagnosis was correct for all 82 patients. Seventy-four of these patients were classified by the FAB system (table II). Forty-two patients had acute myeloblastic leukaemia $\left(31 \mathrm{M}_{1}, 11 \mathrm{M}_{2}\right), 22 \mathrm{had}$ acute myelomonocytic leukaemia $\left(\mathbf{M}_{\mathbf{4}}\right)$, three had acute promyelocytic leukaemia $\left(\mathbf{M}_{3}\right)$, three had acute monocytic leukaemia $\left(\mathbf{M}_{5}\right)$, and four had acute erythroleukaemia $\left(M_{6}\right)$. Seven of the 10 relapses occurred in patients with $M_{1}$ disease (table II).

TABLE II-Classification of leukaemia in 74 long-surviving patients with acute myelogenous leukaemia

\begin{tabular}{lccc}
\hline \multicolumn{1}{c}{$\begin{array}{c}\text { Leukaemia } \\
\text { subtype }\end{array}$} & $\begin{array}{c}\text { FAB } \\
\text { classification }\end{array}$ & $\begin{array}{c}\text { No of } \\
\text { patients }\end{array}$ & $\begin{array}{r}\text { No of } \\
\text { relapses }\end{array}$ \\
\hline $\begin{array}{l}\text { Acute myeloblastic } \\
\text { Acute myeloblastic }\end{array}$ & $\mathrm{M}_{1}$ & 31 & 7 \\
$\begin{array}{l}\text { (with differentiation) } \\
\text { Acute promyelocytic }\end{array}$ & $\mathrm{M}_{2}$ & 11 & 1 \\
Acute myelomonocytic & $\mathrm{M}_{3}$ & 3 & 0 \\
Acute monoblastic & $\mathrm{M}_{\mathbf{3}}$ & 22 & 2 \\
Erythroleukaemia & $\mathrm{M}_{6}$ & 3 & 0 \\
\hline
\end{tabular}

*Later than three years after the induction of complete remission.

Comparisons between patients with a long survival and patients with "standard" survival-Comparisons were made between our 82 patients and 115 patients in Cardiff who entered remission after similar induction treatment but survived for less than three years. There were no significant differences between the groups for sex, blood blast count, or percentage of marrow blast cells (table III). The 82 patients with long survival, however, had significantly higher initial platelet counts $(p=0.001)$ and were slightly younger than the Cardiff patients $(p=0.009)$. They also had a slightly lower total white cell count $(p=0.02)$ and a lower granulocyte count $(p=0.01)$. These differences in platelet count, granulocyte count, and total white cell count persisted when the two sets of patients were stratified into similar age groups. survived for more than three years had received more chemotherapy than other patients with acute myelogenous leukaemia we examined details of induction treatment. Sixty-three patients from 10 of the participating centres were in chemotherapy trials and had received treatment which included cytarabine and daunorubicin (or doxorubicin). Courses of induction chemotherapy varied slightly between centres, mainly in the timing and amount of cytarabine given. Nevertheless, it was possible to compare the total amounts of cytarabine and daunorubicin (or doxorubicin) given to the 63 who had survived for more than three years with that given to all patients for each of the 10 centres; no clear difference was seen. We also compared the number of induction treatments received by each long-surviving patient with the

TABLE IV-Duration of remission and total survival for 82 long-surviving patients*

\begin{tabular}{lccc}
\hline Survival & $\begin{array}{c}\text { No of } \\
\text { patients } \\
\text { relapsing } \dagger\end{array}$ & $\begin{array}{c}\text { No of } \\
\text { deaths } \dagger\end{array}$ & $\begin{array}{c}\text { No of } \\
\text { patients in } \\
\text { the group }\end{array}$ \\
\hline $\begin{array}{l}\text { 3-4 years } \\
\text { 4-5 years }\end{array}$ & 8 & 3 & 82 \\
5-6 years & 2 & 3 & 69 \\
6-7 years & 1 & 3 & 40 \\
$7-8$ years & 0 & 1 & 26 \\
$>8$ years & 0 & 0 & 16 \\
*Data collected and analysed September 1980. \\
+Later than three years after the induction of complete \\
remission.
\end{tabular}

TABLE V-Duration of first remission and total survival for patients who relapsed or died

\begin{tabular}{cccc}
\hline $\begin{array}{c}\text { Case } \\
\text { No }\end{array}$ & $\begin{array}{c}\text { First } \\
\text { remission } \\
\text { duration } \\
(\mathbf{w k})\end{array}$ & $\begin{array}{c}\text { Total } \\
\text { survival } \\
(\mathbf{w k})\end{array}$ & Comment \\
\hline
\end{tabular}

\begin{tabular}{|c|c|c|c|}
\hline $\begin{array}{l}1 \\
2 \\
3 \\
4 \\
5 \\
6 \\
7 \\
8\end{array}$ & $\begin{array}{l}256 \\
342 \\
205 \\
185 \\
192 \\
191 \\
253 \\
158\end{array}$ & $\begin{array}{l}278 \\
363^{*} \\
355 \\
237^{*} \\
200 \\
252 \\
260 \\
364^{*}\end{array}$ & $\begin{array}{l}\text { Died in complete remission: myocardial infarct } \\
\text { Subsequent short second and third remissions }\end{array}$ \\
\hline $\begin{array}{r}9 \\
10 \\
11 \\
12 \\
13\end{array}$ & $\begin{array}{l}285 \\
160 \\
216 \\
162 \\
166\end{array}$ & $\begin{array}{l}299 \\
216 \\
268 \\
=\end{array}$ & $\begin{array}{l}\text { Died with meningeal leukaemia } \\
\text { Exact date of death not known } \\
\text { Exact date of death not known }\end{array}$ \\
\hline
\end{tabular}

*Survival continues.
Remission duration-Analysis of remission duration and total survival for the 82 patients (table IV) showed that eight patients relapsed after three to four years. Forty patients reached five years in continuous first remission and only two patients relapsed subsequently, one in the sixth year and one after more than six years in continuous remission. None of the 16 patients in complete remission for more than seven years has relapsed. A more detailed examination of the patients who relapsed or died is shown in table V. One patient died from meningeal leukaemia, but there was no other example of meningeal leukaemia in the group of 82 long survivors, 75 of whom had not received any form of central nervous system prophylaxis.

Induction chemotherapy-To decide whether patients who had mean number of treatments given to other patients at the same referral centre to achieve remission (table VI). Six patients had required three or more additional induction treatments to reach remission, but reexamination of data from these patients did not suggest that their leukaemia differed in any way from that of the others. Most longsurviving patients had not entered remission more quickly (or more slowly) than other patients with acute myelogenous leukaemia treated at the same centre. Table VII shows the number of days from the start of induction treatment to bone marrow remission for 63 patients compared with the mean number of days to remission for all patients at one referral centre. Most patients had entered remission within 25 days of the mean for their centre, but 10 patients required 
a longer period of treatment (table VII). Closer examination of their blood counts and bone marrow smears at presentation did not suggest any difference from the main group of patients.

Immunotherapy-At eight of the centres most long-surviving patients had been included in controlled trials in which maintenance treatment with chemotherapy alone had been compared with chemoimmunotherapy (at one centre immunotherapy alone had been compared with no treatment). Of 1283 patients included in these trials, $56(4 \cdot 4 \%)$ were long survivors.* Twenty-nine had received some form of immunotherapy, while 27 had received no immuno- patients. Furthermore, we have not seen any relapses in 16 of our patients who have survived for more than seven years.

An assessment of the chance of long survival in acute myelogenous leukaemia is important as it may have a direct relation to the chance of eventual cure. Although our series included patients from 12 different centres, an accurate estimate was possible because eight of the centres carried out trials in which patients at the centre received identical induction chemotherapy, and remission patients were then entered into a con-

TABLE VI-Number of induction treatments to achieve remission for 63 patients treated with drug combinations that included cytarabine and daunorubicin (or doxorubicin) compared with mean number required for all patients with acute myelogenous leukaemia at patient's referral centre

\begin{tabular}{|c|c|c|c|c|c|c|c|c|c|c|c|c|c|c|}
\hline No of treatments: & -3 & -2 & -1 & 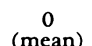 & +1 & +2 & +3 & +4 & +5 & +6 & +7 & +8 & +9 & +10 \\
\hline No of patients: & 2 & 4 & 7 & 21 & 14 & 9 & 1 & 1 & 0 & 2 & 0 & 1 & 0 & 1 \\
\hline
\end{tabular}

TABLE VII-Number of days required to reach complete remission for 63 patients treated with drug combinations that included cytarabine and daunorubicin (or doxorubicin) compared with mean number of days required to reach remission for all patients at each patient's referral centre

\begin{tabular}{|c|c|c|c|c|c|c|c|c|c|c|c|c|c|c|c|c|c|}
\hline $\begin{array}{l}\text { No of days: } \\
\text { No of patients: }\end{array}$ & $-\underset{3}{25-21}$ & $-20-16$ & $\begin{array}{c}-15-11 \\
4\end{array}$ & $-10-6$ & $\begin{array}{c}-5-1 \\
8\end{array}$ & $\begin{array}{c}0-4 \\
10\end{array}$ & $\begin{array}{c}5-9 \\
8\end{array}$ & $\underset{1}{10-14}$ & $\begin{array}{c}15-19 \\
1\end{array}$ & $\begin{array}{c}20-24 \\
2\end{array}$ & $\underset{1}{25-29}$ & $\underset{1}{40-44}$ & $\begin{array}{c}45-49 \\
2\end{array}$ & $\underset{1}{55-59}$ & $\begin{array}{c}65-69 \\
1\end{array}$ & $\begin{array}{c}70-74 \\
1\end{array}$ & ${ }_{3}^{80+}$ \\
\hline
\end{tabular}

TABLE VIII-Effect of immunotherapy on long survival

\begin{tabular}{|c|c|c|c|c|}
\hline \multirow{2}{*}{ Centres } & \multirow{2}{*}{$\begin{array}{c}\text { No of } \\
\text { patients receiving } \\
\text { induction chemotherapy }\end{array}$} & \multirow{2}{*}{$\begin{array}{l}\text { No }(\%) \text { achieving } \\
\text { complete } \\
\text { remission }\end{array}$} & \multicolumn{2}{|c|}{ Long survivors } \\
\hline & & & Immunotherapy & No immunotherapy \\
\hline $\begin{array}{l}1 \\
2 \\
3 \\
4 \\
5 \\
6 \\
7 \\
8\end{array}$ & $\begin{array}{r}100 \\
182 \\
82 \\
370 \\
195 \\
130 \\
152 \\
72\end{array}$ & $\begin{array}{c}42(42) \\
79(45) \\
27(33) \\
139(37 \cdot 6) \\
111(57) \\
47(36) \\
54(35 \cdot 7) \\
59(82)\end{array}$ & $\begin{array}{l}1 \\
2 \\
4 \\
4 \\
9 \\
3 \\
4 \\
2\end{array}$ & $\begin{array}{l}2 \\
3 \\
2 \\
5 \\
7 \\
2 \\
0 \\
6\end{array}$ \\
\hline Total & 1283 & $558(43 \cdot 5)$ & 29 & 27 \\
\hline
\end{tabular}

Only patients entering complete remission were eligible for immunotherapy trials.

therapy (table VIII); there was no significant difference between these figures.

Maintenance chemotherapy-Sixty-nine of the 82 long-surviving patients received maintenance chemotherapy. Eleven of the 13 patients who did not have maintenance chemotherapy were from one centre which included immunotherapy only in its treatment trials. One other patient, the longest survivor, with more than 14 years' continuous remission, was given no maintenance treatment, and one patient refused all further treatment. Eleven centres used maintenance treatment for all patients and it had been given for at least one year (range 1-5 years). The eight patients from these centres who subsequently relapsed had all received maintenance chemotherapy which was standard for their centre.

\section{Discussion}

The possibility of cure for patients with acute myelogenous leukaemia is receiving more attention since reports of long survival have appeared. ${ }^{2}{ }^{3}{ }^{7}$ Our series of 82 adult patients who survived in complete remission for more than three years represents the largest series so far reported, and analysis of our data suggests that patients who have survived for more than five years in complete remission are possibly cured. Only two relapses occurred among the 40 patients who had survived more than five years, a better result then that reported by Freireich et $a l,{ }^{6}$ who noted two relapses after five years in a group of 11

*This figure includes patients from Dartmouth who were included in a multi-institutional study. It has been possible to trace only long-surviving patients from analysed. Consequently, the true figure for long survival may be slightly higher than $4 \cdot 4 "$ ".. trolled trial of immunotherapy. Many of these trials have been reported elsewhere. In all, 1283 patients were treated, with $558(43.5 \%)$ achieving remission and $56(4.4 \%)$ surviving in complete remission for more than three years. These trials were started as early as 1971 and the mean remission rate of $43.5 \%$ would probably be higher with current induction treatments. Although the number of patients surviving for three years would also probably increase, a direct correlation with the remission rate is unlikely because high rates of remission can be offset by relapses after a disappointingly short time..$^{5}$

Although Burchenal's idea that long-surviving patients with acute lymphoblastic leukaemia differed fundamentally from other patients with acute lymphoblastic leukaemia ${ }^{7}$ is untenable now that five-year survival rates greater than $50 \%$ are commonplace, several poor prognostic features have subsequently been shown ${ }^{3}$-namely, high initial blood blast cell counts, the presence of a mediastinal mass, and appreciable enlargement of the liver and spleen. With the subsequent subtyping of acute lymphoblastic leukaemia according to cell surface antigens, ${ }^{10} 11$ additional clinical and prognostic differences in acute lymphoblastic leukaemia emerged. These differences for patients with acute myelogenous leukaemia are not yet clearly evident, but it has been suggested that morphological subtype may be important. ${ }^{12}$ In particular, acute promyelocytic leukaemia may have a more favourable prognosis than other subtypes. ${ }^{13}$

Most of our patients had acute myeloblastic leukaemia $\left(M_{1}\right.$ or $M_{2}$ in the FAB classification) or acute myelomonocytic leukaemia $\left(M_{4}\right.$ in the FAB classification). It was not possible to 
relate closely disease subtype to prognosis, but fewer relapses occurred in the patients with $M_{2}$ and $M_{4}$ subtypes than in patients with $M_{1}$ disease. The importance of this finding is not clear.

Furthermore, we could not show any significant difference in sex, blood blast count, or percentage of marrow blast cells between our 82 long-surviving patients and a group of 115 patients in Cardiff who had entered remission but had had a "standard" survival of less than three years. The long survivors, however, were considerably younger and had significantly higher initial platelet counts. The Medical Research Council have previously reported ${ }^{12} 14$ that age is the chief determinant of prognosis for patients with acute myelogenous leukaemia both for incidence of remission and for duration of survival. Information from the MRC fifth trial of treatment for acute myelogenous leukaemia showed that the initial platelet count was significantly related to the duration of survival but not to the remission rate. ${ }^{12}$ The follow-up was relatively short, however, and the series included only a few patients who had survived for more than two years. Results from other studies show only a marginal relation between age and duration of survival ${ }^{6}{ }^{15}$ or no effect at all. ${ }^{3}$ Most of the few published studies of long survivors in acute myelogenous leukaemia have either not included data on platelet count or have found no relation between initial platelet count and long survival.

There is no obvious explanation for our finding of slightly higher total white cell counts and granulocyte concentrations in the long-surviving patients. The MRC study ${ }^{12}$ showed that the white cell count was significantly but not strongly related to prognosis, survival being slightly worse for patients with high counts.

We also examined the amount and duration of induction chemotherapy received by 63 of our patients in whom treatment had included cytarabine and an anthracycline. It was possible to compare each patient's treatment with standard treatment used to achieve remission for all patients at the referral centre. For many of the long-surviving patients the duration and amount of induction chemotherapy had been standard, and analysis of a small group of patients who had required either more chemotherapy courses or a longer treatment interval to achieve remission did not show differences in bone marrow morphology or initial blood counts. These observations confirm that our group of patients did not include patients with subacute or smouldering leukaemia, whose disease might be expected to have a more benign course.

Several of the centres using immunotherapy have published their results, some of which have shown that immunotherapy prolongs survival. ${ }^{18-18}$ When the data from the eight controlled trials were pooled, however, there was no obvious advantage to the patients who received immunotherapy in terms of their survival without leukaemia for more than three years. This observation adds weight to the view that current methods of immunotherapy have little effect on acute myelogenous leukaemia.

JAW was partly supported by the Leukaemia Research Fund and the British Council.

GGC was supported by public health service grant CA-04326 from the National Cancer Institute.

RPG is a scholar of the Leukemia Society of America and was supported by grants CA-23175, CA-15688, and CA-12800 from the National Cancer Institute and HB-62971 from the National Heart, Lung and Blood Institute.

\section{References}

1 Burchenal JH. Long-term remissions of acute leukemia. Spontaneous and induced. Series Haematologica $1964 ; 1: 47-56$.

2 Jacquillat C, Weil M, Germon MF, et al. Evaluation of 216 four-year survivors of acute leukemia. Cancer $1973 ; 32: 286-93$.

${ }^{3}$ Kawashima K, Suzuki H, Yamada $\mathrm{K}$, et al. Long survival in acute leukemia in Japan. Cancer $1980 ; 45: 2181-7$.

- Gale RP, Cline MJ. High remission-induction rate in acute myeloid leukaemia. Lancet $1977 ; 1: 497-9$.
${ }^{5}$ Rees JKH, Sandler RM, Challener J, Hayhoe FGJ. Treațent of acute myeloid leukaemia with a triple cytotoxic regime: DAT. $B r \mathcal{F}$ Cancer $1977 ; 36: 770-6$.

${ }^{6}$ Freireich EJ, Keating MJ, Gehan EA, McCredie KB, Bodey GP, Smith T. Therapy of acute myelogenous leukemia. Cancer $1978 ; 42: 874-82$.

${ }^{7}$ Fiere D, Martin C, Du Van H, et al. Three years prolonged survival in 16 cases of acute myeloid leukaemia. Nouv Presse Med 1978;7:899-902.

${ }^{8}$ Bennett JM, Catovsky D, Daniel M-T, et al. Proposals for the classification of the acute leukaemias. Br $¥$ Haematol $1976 ; 33: 451-8$.

9 Dow LW, Borella L, Sen L, et al. Initial prognostic factors and lymphoblast erythrocyte rosette formation in 109 children with acute lymphoblastic leukemia. Blood 1977;50:671-82.

10 Greaves MF, Brown G. Antisera to acute lymphoblastic leukemia cells. Clin Immunol Immunopathol 1975;4:67-84.

11 Brouet J-C, Seligmann M. The immunological classification of acute lymphoblastic leukaemias. Cancer 1978;42:817-27.

12 Medical Research Council's Working Party on Leukaemia in Adults. The relation between morphology and other features of acute myeloid leukaemia and their prognostic significance. Br f Haematol 1975;31, suppl:165-80.

13 Bernard J, Weil M, Jacquillat C. Acute promyelocytic leukaemia. In: F Mandelli, ed. Therapy of acute leukaemias. Rome: Lombardo Editore, $1979: 456-60$.

14 Medical Research Council's Working Party on Leukaemia in Adults. Treatment of acute myeloid leukaemia with daunorubicin, cytosine arabinoside, mercaptopurine, L-asparaginase, prednisone and thioguanine: results of treatment with five multiple drug schedules. $\mathrm{Br} \mathcal{F}$ Haematol $1974 ; 27: 373-89$.

15 Freireich EJ. The criteria for curability for adult acute leukaemia. London: Leukaemia Research Fund, 1980.

${ }_{16}$ Zuhrie SR, Harris R, Freeman CB, et al. Immunotherapy alone vs no maintenance treatment in acute myelogenous leukaemia. $\mathrm{Br} \mathcal{F}$ Cancer $1980 ; 41: 372-7$.

17 Whittaker JA, Bailey-Wood R, Hutchins S. Active immunotherapy for the treatment of acute myelogenous leukaemia: report of two controlled trials. Br $\mathcal{F}$ Haematol $1980 ; 45: 389-400$.

18 Reizenstein P, Brenning G, Engstedt L, et al. Effect of immunotherapy on survival and remission duration in acute nonlymphatic leukaemia. In: W D Terry, D Winhorst, eds. Immunotherapy of 'cancer: present status of trials in man. Vol 6. New York: Raven Press, 1978:329-39.

(Accepted 9 December 1980)

JUNIPER BUSH. For to give a description of a bush so commonly known is needless. They grow plentifully in divers woods in Kent, Warney common near Brentwood in Essex, upon Finchley Common without Highgate; hard by the Newfound Wells near Dulwich, upon a Common between Mitcham and Croydon, in the Highgate near Amersham in Buckinghamshire, and many other places. The berries are not ripe the first year, but continue green two Summers and one Winter before they are ripe; at which time they are all of a black colour, and therefore you shall always find upon the bush green berries; the berries are ripe about the fall of the leaf.

This admirable solar shrub is scarce to be paralleled for its virtues. The berries are hot in the third degree, and dry but in the first, being a most admirable counter-poison, and as great a resister of the pestilence, as any growing; they are excellent good against the bitings of venomous beasts, they provoke urine exceedingly, and therefore are very available to dysuries and stranguaries. It is so powerful a remedy against the dropsy, that the very lye made of the ashes of the herb being drank, cures the disease. It provokes the terms, helps the fits of the mother, strengthens the stomach exceedingly, and expels the wind. Indeed there is scarce a better remedy for wind in any part of the body, or the cholic, than the chymical oil drawn from the berries; such country people as know not how to draw the chymical oil, may content themselves by eating ten or a dozen of the ripe berries every morning fasting. They are admirably good for a cough, shortness of breath, and consumption, pains in the belly, ruptures, cramps and convulsions. They give safe and speedy delivery to women with child, they strengthen the brain exceedingly, help the memory, and fortify the sight by strengthening the optic nerves; are excellently good in all sorts of agues; help the gout and sciatica, and strengthen the limbs of the body. The ashes of the wood is a speedy remedy to such as have the scurvy, to rub their gums with. The berries stay all fluxes, help the haemorrhoids or piles, and kill worms in children. A lye made of the ashes of the wood, and the body bathed with it, cures the itch, scabs and leprosy. The berries break the stone, procure appetite when it is lost, and are excellently good for all palsies, and falling-sickness. (Nicholas Culpeper (1616-54) The Complete Herbal, 1850.) 